\title{
11 The Renaissance Ass: Ezio Auditore and Digital Menippea
}

\author{
Tomasz Z. Majkowski
}

In this chapter, I conduct a textual analysis of Ubisoft's game Assassin's Creed II (Ubisoft Montreal 2009) through menippea, a transgressive mode of narrative relying on scandal and paradox to test a philosophical concept, and parody to uncover the game's transgressive potential. This focus may seem strange; the Assassin's Creed series is not usually perceived as offensive or rebellious, despite its many attacks on organized religion, especially Catholicism. Any controversy surrounding this game is more often related to its rather frivolous use of history. On one hand, the game takes liberties in both its visual presentation of the historical setting and its fictionalized recounting of historical events. On the other hand, it creates a sense of historicity and an authentic presentation of past places and events. Several authors have already analyzed this aspect of the game, focusing mostly on anachronism in the game's presentation of Renaissance-era Florence and Rome (Dow 2013; Szewerniak 2016; Westin and Hedlund 2016). Any further debate is silenced by two factors: the game's precautionary disclaimer about the design team's varied ethnic, religious, and ideological backgrounds and the uses of traditional videogame aesthetics. At first glance, then, Assassin's Creed II is just another mass-market sandbox game, faithful to genre rules and player expectations.

Here, however, I expose the way Assassin's Creed II transgresses genre conventions by critiquing three important assumptions of sandbox games. First, I deal with the game's stance on killing enemies and on death in general; then I problematize character development beyond the raising of attribute scores. Finally, I move to the more general issue of freedom that sandbox games are built upon. Focusing on these three problems, I aim to describe how a mainstream videogame can "go beyond the bounds or limits set by commandments or law or convention" (Jenks 2003, 2), not by provoking controversy and outrage among players or the media or by inspiring the player to violate the rules of the game, but in more reflexive ways. My argument is that transgression can be perceived intellectually as well as emotionally. 
The game's transgressive strategies seem to be located within a situational frame (see chapter 3 in this volume) in that the game crosses genre conventions and rules. Yet because Assassin's Creed II also offers a more general criticism of videogame culture by contemplating death, change, and freedom in a broader sense, it seems to lean toward what in chapter 3 of this volume Holger Pötzsch calls a critical frame, but without being overly sensational. This reading opens up another way the game can be perceived as transgressive: in addition to challenging the three issues listed earlier, this chapter also challenges the assumption that only artistic games such as The Path (Tale of Tales 2009) (see chapter 12 in this volume) are capable of dealing with serious topics.

My analysis is motivated by two additional factors. First, the way Assassin's Creed II includes transgressive ideas without violating gameplay and game-mechanical conventions is a result of more general principles ruling character-driven storygames (Ensslin 2014). Perceived from a Bakhtinian perspective, the storygame is a hybrid form that combines the characteristics of several preexisting means of expression, from traditional games to cinema. Moreover, as an interactive form, it creates an impression that the story takes place here and now and is prone to player intervention. A constant tension between various ways to describe the world, all combined within the game, results in parodic tension-that is, a sense of mockery or exaggeration (cf. Majkowski 2015b). Both qualities link the formal aspects of the storygame to the tradition of the carnivalesque (Bakhtin 1984a, 1984b; chapter 3 in this volume), so the genre opens up to transgressive content without necessarily violating its own rules.

Second, I believe the transgressive content of Assassin's Creed II is often ignored or oversimplified in academic analyses. For example, the well-described motif of the double avatar (Compagno 2015; Apperley and Clemens 2016) — the player playing as Desmond Miles while controlling the body of Ezio Auditore and various other assassins-is not just a gimmick devised to bring some critical potential to an otherwise bland massmarket game. The game in fact employs this motif to meditate on certain fundamental issues of human existence: life and death; identity and change; freedom and power. The seriousness of these issues and the transgression of genre conventions that we find in the game are the reasons I use the literary category menippea-which Mikhail Bakhtin calls "a genre of "ultimate questions" (1984a, 115), reaching a serious philosophical subject through playful transgression-as a major analytical tool to examine it. But before I begin a proper game analysis, I want to discuss certain theoretical assumptions regarding menippea. 


\section{Menippea, from Ancient to Digital}

Menippea is a narrative mode that transgresses genre boundaries and combines various genres into a coherent whole in order to distance itself from ideological and aesthetical conventions. This way it questions established truths in new, unexpected ways, either to validate them as universal or to ridicule them as false. For example, Don Quixote (1605) is a menippean novel testing the truth of chivalrous romance and chivalry in general against realistic portrayals of day-to-day country life, which are rather different from a romanticized setting like Arthur's kingdom. Utilizing the menippean form, the novel is able to ridicule knightly ideology yet praise the protagonists' noble and courageous nature.

The term menippea originates in classic Greek satire, supposedly invented by Menippus of Gadara. His style, combining prose and verse to present a narrative based on a certain ideological stance, inspired several Greek and Roman authors to pursue a unique literary mode, distinct from both traditional, didactic satire and adventure romance. From this new tradition, a separate type of European literature was created and appropriated.

Yet it was not until the second half of the twentieth century that this mode was rediscovered and described, when menippean qualities within certain novels, poems, and dramas were brought to light by Northrop Frye (1957) and Mikhail Bakhtin (1984a, 1984b), whose work on Dostoyevsky serves as the basis of my inquiry. Bakhtin (1984a) ties menippea to his concept of the carnivalesque, which he describes as a main vehicle for transporting the unstable, dialogical, and ambivalent values of the carnival into narratives.

Since its introduction to literary theory in the 1960s, menippean satire has been an analytical tool employed to interpret works of classic literature-Shakespearean dramas included (Weinbrot 2005) - as well as to describe properties of the self-reflective, postmodern novel (Kharpertian 1990; Greenspan 1997). My attempt loosely relates to the second practice. I agree with Linda Hutcheon's (1985) point about the necessity to adapt Bakhtinian thought to nonliterary practices because Bakhtin's own preference toward literary analysis was dictated by sociointellectual trends of his own times, and he always stressed the historical dynamics of culture.

\section{The Carnivalesque Properties of Menippea}

In trying to uncover menippea as a pervasive mode within European narrative tradition, Bakhtin distinguishes fourteen aspects of this form, including generous use of humor and general playfulness; employment of fantastical elements and tropes-both 
conventional and innovative; freedom from historical and biographical particularities; the ability to deal with broad philosophical questions; and the tendency to comment on what is important and relevant to particular "ideological issues of the day" (1984a, 118). Within the menippean narrative, contradictory elements and contrasts are played against each other. The protagonist is simultaneously wise and foolish and travels from the heights of Mount Olympus to the lowest slums populated by thieves and prostitutes-and back again. The living have regular colloquies with the dead and the gods, and they all engage in eccentric, scandalous endeavors and situations. Even the narrative style itself is not fixed: menippea switches from prose to poetry and combines various genres and tones, resulting in dialogic tension. The final aim is "the creation of extraordinary situations for the provoking and testing of a philosophical idea, a discourse, a truth" (Bakhtin 1984a, 114). To achieve this aim, menippean texts must employ a carnivalesque worldview and transgress the boundaries of good taste and what is considered proper literary craftsmanship, resulting in scandalous, provocative literature easily disregarded as vulgar (Bakhtin 1984b).

Menippean narrative's whimsical, playful fluidity and its tendency to challenge established rules come from the genre's connection to forces of cosmic laughter: the unofficial, rebellious worldview that manifests itself during carnival festivals and shapes the ideology of menippea, "permeat[ing] both its external layers and its deepest core" (Bakhtin 1984a, 133). The category of the carnivalesque in a game analysis allows us to include the player's active participation as an important factor of the inquiry-the carnival itself is always participatory (Bakhtin 1984a, 122)—while remaining faithful to narrative analysis. As David Annandale observes in his Bakhtinian investigation of Grand Theft Auto: San Andreas (Rockstar North 2004), "Its free roaming form and the extraordinary contingency of its background events make it carnivalesque to even a greater degree than the carnivalesque literature that Bakhtin celebrates, suggesting that the video game may be an art form particularly well-suited to the embodiment of these energies" $(2006,89)$.

The category of the carnivalesque also allows us to describe the transgressive properties of the game because the aim of the carnival itself is to transcend social, aesthetic, and moral borders to create a temporary, upside-down world of ambivalence, where things that are usually divided coexist. To achieve this effect, the carnival produces an arsenal of images, rites, and practices that aim to bring down the high and appreciate the low, to exchange a face with an arse (Bakhtin 1984b, 21).

Many carnivalesque images and practices can be found in videogames, Assassin's Creed II included-from playful violence to the grotesque body imagery to allegories of limitless consumption (Majkowski 2015b). Yet the tone of Assassin's Creed II is different 
from outright carnivalesque titles such as Saint's Row: The Third (Volition 2011), Gears of War (Epic Games 2006), and Mortal Kombat (Midway Games 1992). Its overall tone tries to be more serious; there is an attempt at education in the shape of an in-game encyclopedia; and even violence seems to be toned down. Yet these characteristics are hardly a sign of weakening the carnivalesque properties because menippean narratives can be seriocomical, simultaneously somber in tone and rooted in the joyful relativity of carnival truth (Bakhtin 1984a, 106-108). The menippean properties of Assassin's Creed II depend more on particular images than on an overall carnivalesque atmosphere of freedom from social restraints-although the primary gameplay mode, climbing buildings instead of traversing streets below, has certain carnivalesque properties and blurs the distinction between high and low on a spatial level.

\section{Bakhtin, Parody, and Digital Games}

The main menippean potential of Assassin's Creed II is tied to a generous use of parody, "an integral element in Menippean satire and in all carnivalized genres in general" (Bakhtin 1984a, 127). Parody can be understood as "the creation of a decrowning double" (Bakhtin 1984a, 127), a motif (a character, an event, a plot, an image, and so on) that simultaneously relates directly to another, serious motif within the game but debunks its pathos. Such parody is not necessarily funny (see Morson 1989, 69): to serve its purpose, it "introduces ... a semantic intention that is directly opposed to the original one" (Bakhtin 1984a, 197), therefore exposing both the parodied and the parodying as equally invalid and misguided. The latter characteristic distinguishes carnivalesque parody from simple satire: whereas simple satire addresses ridiculed issues from the position of moral superiority, carnival laughter is universal and deals with both parts of the parodic equation. Its aim is not to replace outdated or inadequate ideas with a new set of more current values, but to force the rebirth of the ridiculed issue itself (Bakhtin 1984a, 126-139). Being the instrument of such cosmic laughter, parody therefore has a quite complicated relation to the idea of transgression in Assassin's Creed II.

A classic example can be used illustrates the concept of the decrowning double. Miguel de Cervantes's book introduces a pair of grotesque twins: the tall, lean, romantic, and deluded nobleman Don Quixote and the short, fat, down-to-earth peasant Sancho Panza. Their simultaneous presence in the novel serves a parodic purpose. The squire ridicules his master's maddened ways from a commonsense position, and the squire's simplicity and practicality are ridiculed by the knight's noble conduct. By masterful introduction of decrowning doubles, Don Quixote describes both chivalrous delusions and peasant practicality as equally laughable. 
My understanding of parody as a major figure of videogame poetics is based on a similar presumption. As stated earlier, the contemporary storygame is a conglomerate of various narrative practices of describing the world, each of which has an ideological background of its own. When they attempt simultaneously to describe the same phenomenon, they often contradict each other, exposing each other's shortcomings in the process. An extreme version of this contradiction creates a "ludonarrative dissonance" (Hocking 2007) - a form of parody invalidating both parodied elements at the expense of the game's coherence.

Such tension is most easily observed in games with strong narrative elements. On the one hand, there is a strong tendency in AAA games to imitate the visual style of cinema and create a plot that unfolds semi-independently of the player's activities. On the other, the same games lure the player with an illusion of freedom of action in an open world. The coexistence of the transfixed narrative and gameplay freedom results in a parodic tension between the two. Plot-related events are multiplied and distorted on the gameplay level to provide the player with sufficient challenge. For example, villainous groups include a ridiculous number of soldiers for the player to dispatch. At the same time, avatar abilities, such as the capability to heal gunshot wounds by crouching behind a wooden crate, are exposed as absurd within the narrative. Just as Sancho Panza ridicules Don Quixote and vice versa, mechanics and narrative are at odds with each other in AAA videogames, constantly reminding the player that neither is the only and proper way to describe the world.

Therefore, I argue that parody lies at the very core of the videogame, although it is rarely perceived. Players and critics more often seek cohesion and describe strong parodic tension as a design flaw, despite this tension's ability to unmask the ideological bias of various genres constituting the videogame (cf. Majkowski 2015a).

\section{Parody and Transgression}

As a figure able to ridicule social, political, and aesthetic norms, parody is a convenient vehicle for transgression in artworks. However, the relationship between parody and transgressive aesthetics is complicated. The presence of a decrowning double (Bakhtin 1984a, 127) exposes the ideological limitation of the parodied original. As W. C. Simons puts it, "Because parody works ... to critically expose how a dominant discourse is limited and bounded ... it is typical and characteristic of a particular era and socio-ideological situation[;] it shows that a dominant discourse is aging, dying, ripe for change and renewal" $(1990,24)$. As such, the decrowning double can serve two purposes: to free the parodist from the dictatorship of what is considered proper and to criticize dominant ideology. Therefore, it can be perceived as "a threatening, even 
anarchic force, one that puts into question the legitimacy of other texts" (Hutcheon 1985, 75).

But the work of parody is paradoxical: its existence depends on what is parodied. Therefore, without the original and its ties to the dominant discourse, a parodic gesture is pointless, and "parody's transgressions ultimately remain authorized-by the very norm it seeks to subvert" (Hutcheon 1985, 75). It can thus be argued that Bakhtin's idea of carnival falls short in that carnival is short-lived and licensed by the authorities. By extension, a weak point of the concept of the carnivalesque is also revealed: it operates within the limits established by official discourse. This is the way David Annandale (2006) analyzes Grand Theft Auto: San Andreas, pointing out the game's inability to address various important social issues.

Yet such criticism is valid only if the carnival and the carnivalesque are treated as forces of social and political change that fail to achieve their goals and ultimately reinforce the status quo (see chapter 3 in this volume). But the transgression committed by the carnivalesque is rarely tied so closely to the political ideal of subversion. Instead, it can be a "deeply reflexive act of denial and affirmation" of the norm (Jenks 2003 , 2), a way to bring to attention the very existence of a moral, aesthetical, or social boundary. With this purpose in mind, an "ambivalent carnival laughter burns away all that is stilted and stiff, but in no way destroys the heroic core of the image" (Bakhtin 1984a, 133).

\section{The Creed of the Assassins}

Assassin's Creed II is a sequel to Assassin's Creed (Ubisoft Montreal 2007) and the second of a twelve-game main series, which has eleven spin-offs. In the first four games, the player controls Desmond Miles, a modern-day bartender who turns out to be a scion of a long line of Assassins-members of a secret order waging a shadow war against the Templars over the faith of the world. The stakes are high as the Templars try to create a world of rational order by depriving humanity of free will, and the Assassins, champions of freedom, try to prevent that.

Plugged into the Animus, a device that allows access to genetic memory, Desmond relives the adventures of his Assassin ancestors. The first game allows him to visit Palestine during the Third Crusade. The second game, which is the subject of this analysis, relocates the series historically and introduces a new ancestor, the Renaissance Italian nobleman Ezio Auditore da Firenze.

During the course of Assassin's Creed II, Desmond relives several key episodes of Ezio's life, from his birth in 1459 until his first encounter with the mysterious Precursors in 
1499. Desmond witnesses a conspiracy that leaves Ezio's father and brothers falsely accused of treason and executed and that involves the cardinal Rodrigo Borgia, who later is elected Pope Alexander VI. Tracking the conspirators, Ezio discovers that his father was a member of the secret Assassins Order and that Borgia is the leader of the enemy Templars. The game ends with Ezio beating up the pope in the Sistine Chapel, before discovering beneath the chapel the ruins of a civilization predating humanity. The Precursors created a technologically advanced culture that vanished from the earth millennia ago but is still remembered as the pantheon of Roman gods. During a confrontation with a hologram of the long-dead Minerva, Ezio learns that the real stake in the war between the Assassins and the Templars is control over the Precursors' artifacts.

The game is played from a third-person perspective, with the camera over Desmond's and Ezio's shoulders. In the first few minutes, the player takes direct control over Desmond, but once Desmond is plugged into the Animus, Ezio becomes the player's avatar, and modern-day buildings are replaced with a full historical environment. The head-up display, containing a map, a health bar, and mission details, appears only when the player is playing Ezio, implying that it is the Animus interface.

Desmond's episodes are short and played in a limited space. In contrast, Ezio is free to roam the re-creation of four Italian cities: Florence, Venice, Montereggioni, and San Gimignano (with parts of the Vatican in the finale), either walking through crowded streets or climbing buildings and traversing rooftops. The story progresses through a series of short quests. There are many additional activities, from gathering collectibles to making sidequests unrelated to the main plot. Although the game emphasizes the need for secrecy and introduces a number of stealth mechanics, open combat is hard to avoid, and stealth is most crucial during some of the storyline missions, when being discovered can result in failure.

If Ezio dies or is unable to complete a storyline mission, the game reloads from the last save point, informing Desmond and the player about desynchronization: apparently, the modern-day hero cannot diverge too much from his ancestor's life but must repeat the memory correctly. A similar mechanism is introduced to explain why access to certain areas opens up as the game progresses.

Assassin's Creed II can be easily connected to Bakhtin's fourteen-point description of menippea (1984a, 114-118). The game combines fanciful, fantastic tropes of reliving through technological devices the memories of distant ancestors in a meticulously recreated, historical open world. This world shows every sign of Bakhtinian slum naturalism (Bakhtin 1984a, 115) as Ezio recruits prostitutes, thieves, mercenaries, and other lowlifes as allies. The protagonist adopts various ideological stances and tests them 
during changing circumstances-while doing so, he regularly confronts the dead and dying. He, too, is a dead man, just a digital shadow of the fifteenth-century Italian nobleman-a shadow inhabited by both Desmond and the player. The world is full of contradictory and eccentric characters, from a brothel-operating nun to the villainous, heretic pope. During the game, the player takes part in carnival festivities and meets an Olympian goddess.

Although this analysis is certainly valid as an opening move, it should be supplemented by two important inquiries. First, we need to take into consideration the difference between literature and videogames, at least to signal the tensions and intersections between player choices and game story (Kapell 2016). Second, we must check what kind of truth the menippea puts to the test and what norms are transgressed-an important step when analyzing a game with the tagline "Nothing is true, everything is permitted."

To do both, I focus on what is parodied within the game. Assassins Creed II provides handy examples of decrowning doubles. The protagonist, Ezio, has several doubles. He serves as an avatar for the player as well as for his modern-day double, Desmond Miles. Within his timeline, he is contrasted with Vieri de'Pazzi, his equivalent from a Templarrelated family, and with Rodrigo Borgia (Compagno 2015). The final combat of the game turns out to be fisticuffs with a rather unassuming, corpulent priest dressed in pontifical robes and parodies the convention of the final boss fight while decrowning Rodrigo Borgia. But as fun as creating such pairs is, the game has more general parodic aspects. Most crucial, several elements of the narrative are parodied by their equivalent on the gameplay level, opening the game up to a menippean reading.

Dealing with grand topics is the main goal of menippea, according to both Bakhtin's and Frye's interpretations of the form. Menippea challenges established knowledge, opposes myth and intellectual laziness (Frye 1957), and serves as the trial of a philosophical idea to cleanse it from everything petrified and pathetic (Bakhtin 1984a). In this way, it reaches the potential to transgress both good taste and sanctioned knowledge, to shake up what was already petrified by social norms, and to reach toward a universal, fundamental truth of human existence. In the next section, I elaborate on the topics of death, change, and freedom by exposing contrasting, parodic elements of Assassin's Creed II, especially Ezio Auditore's foolery. I start with death because the game announces the topic of killing in its title. Then I interpret the protagonist's everchanging character and ideology and finally move on to a discussion of freedom, the central problem of open-world sandbox games. Thus, I scrutinize whether a marketoriented, seemingly benign videogame is capable of transgressing norms and addressing serious issues without being outright preachy. 


\section{Requiescat in Pace}

In The Golden Ass (late second century AD [Lucius Apuleius 1999]), the only ancient menippean novel that has survived in its entirety, the protagonist Lucius is turned into the eponymous animal. He suffers great misadventures and, in consequence, transforms from a seeker of carnal pleasures to a priest who leads a more meaningful and spiritual existence. He also learns about love, mercy, and the cruelty of fate (Bakhtin 1981; Freudenberg 2005). Ezio Auditore's situation (and that of his doppelgänger Desmond Miles) is very similar. He is taken from the comfort of a privileged life as the son of a wealthy banker and transformed. As the storyline unfolds, he is forced to try out a new set of ideas and values and finally reaches peace, learning what those values mean in practice. The lesson learned is indeed important: it is about death. And because the protagonist serves as the avatar of not just one but two different entities-Desmond and the player-his experiences also allow them to learn the same lesson.

The topic of death is introduced in the very first Ezio scene: as an infant, the protagonist almost dies. He is saved, but only to serve as a vessel for somebody else and for a purpose that is not revealed to him until the end of the game. As a young man, Ezio witnesses the unjust and unpreventable death of all the men of his immediate family. Hunted by the law, deprived of wealth and privilege, he is ejected from society (one may say he symbolically dies) and must assume a new persona: that of an outsider and an avenger. The narrative change is stressed on a gameplay level as the combat changes. Up to this point, Ezio was just brawling with his rival and his cronies. But the very moment the player regains control after the cutscene that shows the execution of the Auditore family, the first real swordfight occurs, resulting in the death of Ezio's opponents. He shows no remorse after the event; he only thirsts for more vengeance. This obsession serves as a justification for the first assassinations that the player must execute. Then, as Ezio becomes Assassin-in-training, he starts justifying killing by referring to the Assassins Order ideology. He also tries to show respect for his victims by acting as their confessor and gently guiding them to the other side. He almost always fails.

Gameplaywise, certain storyline missions require the player to assassinate a member of the Templar conspiracy. Success results with a "meaningful death" sequence. It starts with Ezio/the player stabbing his target. Then the gameplay pauses to play a "threshold dialogue." The scene is strange in a videogame but common in the menippea, with the protagonist arguing to be let in through the door. Sometimes, as in the case of Seneca's The Gourdification of the Divine Claudius, the door leads to the afterlife (Bakhtin 1984a; Greenspan 1997). In Assassins Creed II, the scene at the threshold of death is 
very prominently presented. Against a blank background, Ezio holds his victim almost lovingly and exchanges final words, trying to glean some important information or commenting on the sins of his target.

His attempts are either resisted, as when the victim insults or mocks Ezio for the last time, or partially succeed, as when he learns incomplete information. Then, after the victim dies, Ezio tries to say something profound, usually in Italian. Finally, he says, "Requiescat in pace," a Latin phrase strongly associated with Christian burial rites, meaning "May he rest in peace." With this final remark, the whole scene becomes contradictory: the killer is masquerading as a priest administering the last rites even though there is no indication that Ezio believes in the afterlife. Moreover, the visual aspect of the scene, with Ezio holding the victim in his arms, is closely reminiscent of the pietà, the archetypal pose in which the Virgin Mary grieves over the dead body of Jesus.

The final conversation between Ezio and his victims serves mainly as a justification of the assassination. If the victim tries to excuse the actions for which Ezio kills him, the assassin refuses his confession and points out that the victim has only himself to blame, a response in direct opposition to absolution. Sometimes it is Ezio who regrets his deeds and explains the murderous act as an inevitable result of circumstances. In the absence of God or any other form of higher justice, the assassin presents himself as a deliverer of justice in the form of a death sentence. However, he is not a judge, capable of condemning or exculpating someone. He is just an auditor-the impassive deliverer of an inevitable result.

The solemn, serious atmosphere of the meaningful death sequence is contrasted with the player's satisfaction after completing a difficult and lengthy quest. The assassin, delivering the killing blow, is depicted not only as a priest delivering last rites but as a mourning mother. The final conversation parodies the way such exchanges are presented in popular culture: it lacks any deep meaning and never results in conciliation. Moreover, in the game's finale Ezio is revealed as an impostor, faking stoic impartiality in killing but still seeking revenge. The very idea of a meaningful death is thus questioned, and justifications for the act of killing are invalidated.

\section{The Trail of Bodies}

The game undermines the idea of an assassin being the auditor of human life in another way as well. As soon as the death scene ends, the game resumes, and, just like before the scene, the player must dispatch a horde of enemies, typically the dead target's bodyguards. The resulting combat is full of flashy moves and cinematic finishes and is completely deprived of any moral justification. Killing generic thugs is Ezio's bread 
and butter, and his body count is so impressive that subsequent games in the series acknowledge it.

The body-count problem could be dismissed if these enemies were presented as lifedeprived target dummies. But the game problematizes Ezio's mass murdering by giving the grunts a personal life. Scenes show the brutes playing cards, getting bored at their posts, and conversing about the money they will bring home to their families. None of this appears to move Ezio, nor apparently does it affect the player, who has no choice but to participate in Ezio's killing sprees, or Desmond, who only takes the opportunity to hone his own killing techniques in the Animus. After all, he is just reliving his ancestor's life and has no power to affect it.

The contrast between the importance of certain deaths and the lack of a sense of others' significance reveals several parodic contradictions. The first one is between the game narrative and gameplay: the narrative tries to remain serious about death, whereas gameplay carnivalizes it (Majkowski 2017). The second is between the position of the player and the protagonist. Ezio craves absolution and constantly justifies himself, but the player knows that killing in videogames is just something one does to progress without giving it too much thought-as if questioning game violence is the province of media enemies only (Nauroth, Gollwitzer, Bender, et al. 2014).

The third and most important contradiction shows the crack in the titular creed and the order upholding it. Although the Assassins are fighting to free common men from oppression, in fact they care only about important figures of power. Other people are only a means to an end: they provide moral justification for the actions carried out for the Assassin Order. On the gameplay level, most other people are deprived of agency and wander the streets aimlessly. If the player is not using them for cover, they are just nuisances, blocking the avatar's movement and commenting on his actions. They are civilians, people Ezio does not kill, as the game reminds the player every time she stabs a random figure-although the very possibility of such action reveals a tension between game narrative and gameplay once again. Some of the civilians are marked as more important-the peddlers and courtesans, thieves and mercenaries whom Ezio can hire as support. The gameplay significance of these figures comes with a narrative price, however, in that they are deprived of even a pretense of life. They exist only to aid the protagonist in achieving his task, unable to move from their spot when not following the assassin and obeying his orders.

Common men turn into collateral damage if they side with the Templars, even if they are driven by the poor economic condition that the Pazzi family guards complain about. Yet this narrative motif is contrary to the ideal the Order supposedly upholds: that of the free will. The people are free to choose as long as they choose correctly. 
Moreover, the reluctance to kill unarmed civilians is contrasted with the joy of murdering defenseless guards. As an assassin, Ezio does not give the opponents any opportunity to defend themselves, preferring stealth tactics, a preference that in turn contrasts with Ezio's supposedly honor-based quest for vengeance (Yie 2017) that is executed only in confrontation with major enemies, who deserve their own death scenes. But, then again, the division of the nonplayer characters into four factions-civilians, henchmen, enemies, and targets_can be dismissed as artificial because all of them are governed by the same rule set and all can be stabbed with the same hidden blade. As much as the mechanics of killing separate people into categories, they make them equal at the same time.

\section{Ezio the Ass, or Metamorphosis}

Among the most important of Ezio's qualities is his ability (or inability) to learn and change. During the course of the game, the assassin goes through several transformations, changing his social standing, his worldview, and abilities. At the very beginning, Ezio changes from an infant in the first scene into a member of the Florentine nobility and establishes himself as a romance hero in the world of feuding Italian families. The theme is stressed by two indirect quotations from Shakespeare's Romeo and Juliet: the fight on Ponte Vecchio resembles the opening of Shakespeare's drama; then Ezio climbs to his beloved's bedroom and spends a night there. The lighthearted tone of the beginning is soon transformed into something darker, as also happens in the well-known play. But the romantic trajectory is confronted with a political one, and there is no more room for Ezio's romance, so the storyline disappears from the game. When the male members of the Auditore family are hanged, the only survivor changes again, this time into an avenger without any regard for romantic love, at least until his honor is satisfied. All the narrative transformations are stressed both on the visual level, as Ezio dons his assassin's costume, and within the gameplay, as the ability to kill enemies is unlocked. The sudden change of topic introduces an important menippean quality of the game: the ability to adapt to new kinds of ideological truth.

In his analysis of Assassin's Creed II's semiotics, Dario Compagno (2015) stresses the importance of Ezio's confrontation with Vieri de'Pazzi in San Gimignano. It is, indeed, the moment of the next transformation in which Ezio tries to discard his personal quest for vengeance in favor of public service. The tension between the personal and the public plays out as a story of a hero's gradual maturation from having purely selfish motivations to becoming a public servant, similar to the trajectory in Apuleius's The Golden Ass. But this trope is complicated by introducing the analyzed issue of death. 
To become a proper political animal, Ezio changes from innocent infant to brash yet harmless youngster and then cold-blooded killer who resolves all problems by spilling blood. But this path of maturation is then rejected as invalid. At the end, Ezio must surprisingly embrace Christian values, end the bloodshed, and confront God, who, quite ironically, turns out to be a female ancient alien, disguised as a pagan deity. At the beginning of the sequel, however, the new set of values also turns out to be false. Once again the protagonist's decision, which at first is presented as valid and profound, turns out to be rash and foolish.

Indeed, for most of the game Ezio is either misguided or clueless, and even as he works to uncover the reason behind his misadventures, he usually fails. Each ideological stance he adopts is dismantled the same way: it turns out the protagonist is either mistaken or deceived. When his family is imprisoned, young Ezio seeks help from the very person behind the false accusations. While pursuing his personal vendetta, Ezio accidently uncovers political conspiracy. As soon as he finally emancipates himself from the need for vengeance, he finds himself extremely close to avenging his family.

But the most delicious unveiling comes right after Ezio defeats Rodrigo Borgia for the first time. Ezio's assumption that he has been acting on his own will to achieve victory and maturity is shattered. He suddenly discovers there were no coincidences and that what he mistook for his own achievements were only parts of the assassin's training. All strange and dangerous adventures were carefully curated by the Assassin Order, to which his supposedly unrelated allies all belonged. And as soon as Ezio comes to terms with this new situation, he is enlightened again. When he meets the holographic image of Minerva, the goddess suddenly starts talking directly to Desmond, knowing he will relive Ezio's memories in the future. This way, Ezio realizes that he is insignificant and all his misadventures were staged by a long-dead alien being, whose goal was to deliver a message Ezio does not care about to a person he will never meet, a passenger in his own body.

Thus, the game comments on several genre conventions. First, it violates the idea that the main character should be ideologically stable, relentlessly pursuing his or her goal from the beginning to an end, like Nathan Drake or Lara Croft. Second, it opposes the idea that during the game narrative both protagonist and player accumulate knowledge so that they have a better understanding of the world, necessary to conquer the final challenge. Finally, it comments on the assumption that the protagonist's efforts matter and only he is able to save the world when Ezio's fight against the Templars turns out to be insignificant in light of the impending cosmic catastrophe Minerva informs Desmond about. 


\section{The Renaissance Fool}

But with all his naïveté, Ezio serves an important role. As a clueless outsider, he has the potential to uncover what is hidden and to question what is believed to be true. The first quality comes to play quite often. As soon as he is ejected from society, Ezio starts to peep and to eavesdrop. He frequently follows people to places where they feel safe and sees them without their public mask, exposing their pettiness and hypocrisy. This skill, combined with his inability to maintain proper social norms, provides an outsider's perspective and enables social critique. It also allows the player to put Ezio Auditore in line with a distinguished dynasty of literary fools, such as Lucius in The Golden Ass, Parsival of the Round Table, Simplicissimus, and Gulliver in his travels.

This way Ezio becomes a transgressive figure par excellence because, as Bakhtin would put it, he gains "the right to be 'other' in this world, the right not to make common cause with any single one of the existing categories that life makes available; none of these categories quite suits them, they see the underside and the falseness of every situation" (1981, 159). Ezio's ability to dismantle social norms by associating with thieves and prostitutes to fight a corrupt elite is stressed by the eccentricity of his looks and behavior. He dresses in unique and distinct clothes: he is branded as outsider and assassin by an easily recognizable hood. He also acts in a very peculiar way, not following the loops created by game artificial intelligence. He has freedom of movement but pays for it: when in a crowd he constantly bumps into people, knocks them over, and cannot maintain his pace when walking. He also climbs walls and roofs, which does not go unnoticed, and there is always a voice commenting it. Unseen bystanders are either calling him an idiot or a madman for his behavior or speculating about his private affairs: Is he drunk or in a hurry to meet his mistress? There is no respect or admiration in those remarks. Instead, he is constantly abused by the crowd he is trying to protect. This way Ezio's honorable quest and serious methods are degraded through the familiar, vulgar, and disrespectful language of the marketplace, one of the most prominent aspects of carnival (Bakhtin 1984b).

Ezio's foolery has one additional purpose: he serves as a mask for somebody else. Not only is he simultaneously a protagonist and an avatar-the player's embodiment within the gameworld (Burn and Schott 2004; Klevjer 2012; Jørgensen 2013; Vella 2014)_but also the control the player has over Ezio is indirect, mediated by an already established protagonist-avatar, Desmond, which complicates the relationship between the player and the playable figure. As Tom Apperley and James Clemens put it, "This game, and the rest of the Assassin's Creed series, renders the issues [of avatar control] in a way that self-reflexively stages the processes of focalization, localization, integration and programming for its players. This is a peculiarity of the series, but this offers crucial 
transparency on this important aspect and elements of the player/avatar relationship" (2016, 122).

The player experiences the Renaissance world from the perspective of a fool and outsider. Thus, it is possible to playfully question parts of the established knowledge by exposing its falseness, even if everything seems to be in order at first glance. The effect is doubled by the presence of Ezio's doppelgänger Desmond, who appears undereducated and needs constant explanations. Those explanations are delivered by the historian Shaun, whose disdain toward Desmond's stupidity stresses the game's general attitude toward official historical knowledge as oppressive and unplayful. The visits to Renaissance Italy are constantly interrupted by Shaun's unhelpful tirades, so the impression of Ezio being only a mask is enhanced. But it is also worth noting that all abusive comments, although filtered by the two avatars, are aimed directly at the player. It is the player who makes Ezio clumsily navigate crowded streets or forces him to climb-and be ridiculed for it. Shaun's historical commentaries are there to educate because the implied player does not possess sufficient knowledge of Florence's topography or the fine details of Pazzi's plot. Therefore, the game abuses the player as much as it abuses both avatars, simultaneously turning them into scapegoats the player can blame for her own shortcomings in operating the interface or recognizing important historical landmarks.

And historical background information is only one way the game reminds the player that she has not been transported into the historical past but is experiencing only a simulation: there are glitches onscreen, the map and menu have very distinctly modern looks, and so on. Ezio's role as an avatar is taken one step beyond the conventions. Not only is he controlled by Desmond, who in turn is controlled by the player, but the game control scheme also turns him into a marionette, with limbs attached to controller buttons. Instead of attacking, the player must press the "armed hand" button, and when she wishes to speak, she must press the "head" button. Ezio's body is even further degraded because it is usually observed from behind, with his backside prominently displayed, especially during climbing, and his face covered by the hood. The constant shift between exposing Auditore's face in cinematics and exposing his derriere in gameplay sequences serves as a classic carnival inversion of the face and the buttocks (Bakhtin 1984b, 21).

Yet the situation of control remains paradoxical. As Apperley and Clemens observe, to operate the game successfully, the player needs to incorporate the controller scheme. During gameplay, the player's body is immobilized in front of the screen, and her fingers operate the controllers, a position parodied by Desmond's total immobilization inside the Animus (Apperley and Clemens 2016, 119-121). Moreover, the particularity 
of the Assassin's Creed II controller scheme results in forming a muscle strain that the game community jokingly calls "the assassin's claw" (Ubisoft Forum 2012). The game demands that the player press and hold the right trigger on the gamepad, so the constantly bent index finger becomes sore. But it is in this way that the player is revealed as being controlled by Ezio and performing his movements to the point of physical discomfort.

The marionette metaphor reveals yet another aspect of Ezio's foolery. As already established, he is misguided about his deepest conviction. He believes himself to be a free man fighting for the freedom of others and perceives members of the Assassin Order as defenders of free will against the Templars. The way the message about the Order is delivered to Ezio even convinces the player. But it is constantly contested. First, the Assassins are revealed as the force behind most of Ezio's adventures. Second, the player is constantly reminded that she is steering Auditore via sophisticated technology: This motif reaches its culmination when Ezio is revealed to be nothing but an avatar also on the narrative level when the goddess Minerva addresses Desmond directly, using Ezio as a medium.

The opposition between Ezio's beliefs in freedom and practice is ever present. In the narrative, he rarely acts on his own volition; he is usually forced to action by external circumstances. As an avatar, he is also shackled, doing exactly what the player makes him do. But the player is also manipulated in that the game poses as an "open world" when it is in fact is quite linear, with several parts of the game world opening and closing on narrative demands. There are possible yet forbidden activities-murdering "civilians" being the most prominent among them. Deviation from the established narrative results in desynchronization and the collapse of the game, so in reality the player has exactly as much freedom as her grotesque double, Ezio. This contradiction is emphasized by the overall narrative frame: playing as Desmond, the player is just recreating actions Ezio already accomplished in the past. A constant fight for freedom is thus simultaneously revealed as an ultimate lack thereof.

\section{Conclusion}

Assassin's Creed II addresses two videogame issues through contradictions present in a single motif or image: the problem of violence and the player's freedom. This duplicity of game elements creates several "decrowning doubles," especially in the interaction between narrative and gameplay, although this trope is ever present also in the narrative itself. Constant contradictions, paradoxes, and the tendency to ridicule any attempt to address what is usually perceived as a serious issue stress that a definite answer is impossible. 
The way Assassin's Creed II employs contradictions and creates doubles can be traced back to the way the game is constructed. The way the game is played and the story is told result in tension, often perceived as dissonance. Assassins Creed II exploits this tendency of the game genre to take a stance on different dilemmas haunting videogameswhether death should be treated in a playful or serious way; whether the protagonist should be a heroic figure; and whether the player is free to act within the game world or is just another piece in the game machine. By exploring various answers, the game creates an intellectual test, transgressing both genre expectations and the typical ideological background of mass-market videogames.

It is worth noting that the game achieves its transgressive status without violating the overall sense of coherence during play or heavily deviating from the sandbox genre. It is easy to dismiss subtle yet transgressive parts of the game as a conglomerate of design flaws or inconsistences typical to every storygame. This tendency gives validity to menippea and the carnivalesque as both interpretative frameworks, enabling a perspective that uncovers important aspects of the game, and cultural modes behind narrative-heavy videogames in general. Assassins Creed II is just a convenient and persuasive case because it poses easily observed menippean qualities, such as reliance on parody in the Bakhtinian sense and a tendency to combine genres and to blend realism and fantasy. It also relies on motifs that are characteristic of menippean narratives, such as the threshold dialogue, the fool as a protagonist, and metamorphosis as a plot device. But in the videogame genre as a whole, the menippea is not limited to this example, and the tendency to perceive transgressive qualities as something common in videogames suggests that the whole genre is tied to the carnivalesque.

Assassins Creed II shies away from definitive answers to the questions it raises, so it is hard to tie the game to a particular ideology, at least regarding issues of death and freedom. This is another general carnivalesque quality. The only version of truth allowed by the carnival is transgressive and ambivalent because carnival resides between various ideological and narrative positions, freely crossing aesthetic and moral boundaries. As such, it cannot be explained, but it can be experienced. For this very reason, videogames, a cultural form well suited to presenting that experience, turn out to be a very appropriate medium for menippea-perhaps even more so than the novel. 